\title{
Loss of Phosphatase and Tensin Homologue (PTEN) Expression Associated with Higher Risk Grade Group Gleason Prostate Adenocarcinoma in Sanglah Hospital Denpasar
}

\author{
Tjandra Kristiana 1, I Gusti Ayu Sri Mahendra Dewi 1, Luh Putu lin Indrayani Maker ${ }^{1}$, \\ Herman Saputra ${ }^{1}$, Ni Putu Sriwidyani ${ }^{1}$, I Made Muliarta ${ }^{2}$ \\ ${ }^{1}$ Anatomical Pathology Department, Faculty of Medicine Udayana University, Sanglah Hospital, Denpasar, Bali, Indonesia \\ 2 Physiology Department, Faculty of Medicine Udayana University, Denpasar, Bali, Indonesia
}

\section{ARTICLE INFO}

Received : 12 September 2019

Reviewed : 17 October 2019

Accepted : 11 November 2019

\section{Keywords:}

immunohistochemistry, prostate adenocarcinoma, PTEN expression, risk grade group Gleason

\author{
*Corresponding author: \\ I Gusti Ayu Sri Mahendra Dewi \\ Anatomical Pathology Department, \\ Medicine Faculty of Udayana \\ University, Sanglah Hospital, \\ Denpasar, Bali \\ mahendradewi@rocketmail.com
}

\begin{abstract}
Background: Prostate cancer is the second most common malignancy in men and the fifth most common cause of death worldwide. In Asia, $59.3 \%$ of patients come for the advanced stage treatment. PTEN inactivation is identified in about $20 \%$ of primary prostate tumors in radical prostatectomy and the loss of PTEN is associated with poor clinical and pathological outcomes. The purpose of this study is to prove that there is an association between PTEN expression and risk grade group Gleason prostate adenocarcinoma in Sanglah Public Hospital, Denpasar.
\end{abstract}

\begin{abstract}
Methods: This is a cross-sectional study. The sample size of this study was 35 paraffin blocks. These samples were selected by proportional stratified random sampling from hematoxylin-eosin preparation. Prostate adenocarcinoma was regrouped into 3 categories based on NCCN risk stratification: low risk grade group Gleason (Gleason score $\leq 6)$ ), intermediate risk grade group Gleason (Gleason score 7), and high-risk grade group Gleason (Gleason score 8-10). Immunohistochemistry examination of PTEN was performed and the expression was evaluated by scoring method. The data were analyzed by Chi-square and logistic regression.
\end{abstract}

Results: The analysis result showed that there is an association between PTEN expression and risk grade group Gleason that is statistically significant. The loss of PTEN expression associated with higher risk grade group Gleason is of the higher proportion with $p=0.001 ; \mathrm{PR} \mathrm{3.339;95 \%} \mathrm{Cl:}$ 1.296-8.599, but there is no association between the proportion loss of PTEN expression heterogeneously or homogeneously and the risk grade group Gleason with $p=0.742$; PR 0.663 ; $95 \% \mathrm{Cl}: 0.179-2.457$.

Conclusions: This study has proved that PTEN expression is associated with higher risk grade group Gleason prostate adenocarcinoma.

\section{INTRODUCTION}

Prostate cancer is the second most common malignancy and the fifth most common cause of death due to malignancy worldwide [1]. It was reported that 94,000 deaths occurred in Europe in 2008 and more than 28,000 deaths in the United States in 2012. In Asia, the average incidence of prostate cancer is 7.2 per 100,000 men per year. In Indonesia, the number of patients with prostate cancer at three central hospitals (Jakarta, Surabaya and Bandung) over the past 8 years was 1,102 patients, with an average age of 67.18 years. Around $59.3 \%$ of the patients came for the treatment at an advanced stage. Provinces in Indonesia with the highest prevalence of prostate cancer are Yogyakarta, Bali, North Sulawesi and South Sulawesi [2].

Based on World Health Organization (WHO) classification 2016, prostate adenocarcinoma consists of acinar and ductal adenocarcinoma and acinar adenocarcinoma is the most common type. The grading system of adenocarcinoma prostate has been proposed by Dr. Donald Gleason based on architectural patterns. Two most common architectural patterns consist of score 1 (the most differentiated) until score 5 (the least differentiated) [1,3]. The Gleason score will later be written in the sum and produce a grade group (1 to 5). Grade groups are more superior than Gleason scores to determine prostate cancer risk groups. Based on 
NCCN (National Comprehensive Cancer Network) risk stratification, Gleason scores are grouped into 3 categories: low risk grade group Gleason (gleason score $\leq 6)$, intermediate risk grade group Gleason (gleason score 7), and high risk grade group Gleason (gleason score 8-10) [1].

PTEN is a tumor suppressor gene that is most often inactivated in human cancer, especially in endometrial carcinoma of the uterus, glioblastoma and spinal tumors, prostate carcinoma, bladder, adrenal gland, thyroid, breast, skin (melanoma) and colon. PTEN controls the signaling of phosphoinositide 3-kinase (PI3K) which has an important role in various cellular functions. PTEN is involved in cell proliferation and survival, energy metabolism and cell architecture [4,5]. Inactivation of PTEN (deletion and mutation) is identified in about $20 \%$ of primary prostate tumors in radical prostatectomy samples and the loss of PTEN is associated with poor clinical and pathological outcomes $[6,7]$.

Hamid et al. [8] examined the association of expression of PTEN by fluorescence immunohistochemistry with lethal prostate cancer in men treated with prostatectomy. They divided the Gleason grade group into 3 categories: 6,7 , and 8-10. They found that low PTEN expression in primary prostate cancer detected by fluorescence immunohistochemistry was an independent prognostic biomarker for metastasis and death after definitive therapy. Lotan et al. also found that the loss of PTEN expression on immunohistochemistry was significantly associated with higher Gleason scores $(p<0.0001)$, extraprostate expansion $(p<0.0001)$, seminal vesicle invasion $(p=0.0009)$, and pathological stage $(p<0.0001)$. In their study, they divided the Gleason score into $\leq 6,3+4,4+3$, and 8-10.7

The purpose of this study is to prove that there is an association between PTEN expression and grade group prostate adenocarcinoma in Sanglah Public Hospital, Denpasar.

\section{METHODS}

\section{Samples}

This study uses a cross-sectional design. The sample size of this study was 35 paraffin blocks. These samples were selected by proportional stratified random sampling. The Gleason grade group was used as a stratification group. The paraffin block of the prostate adenocarcinoma patient who performed TURP (transurethral resection of prostate) or prostatectomy was examined histopathologically at Anatomical Pathology Laboratory of the Faculty of Medicine, Udayana University/Sanglah Hospital Denpasar, from January 1, 2015 to December 31, 2018. This study has received permission from Research Ethics Commission of Udayana University/Sanglah Hospital ethical clearance letter's reference number 1833/UN.14.2.2.VII.14/LP/2019.

The inclusion criterion is paraffin blocks from prostate adenocarcinoma patients who have undergone TURP or prostatectomy and contain sufficient tumor tissues. The exclusion criteria are 1) paraffin blocks that do not contain enough tumor mass, or damaged or moldy or not found and 2) the variant of prostate adenocarcinoma which is difficult to determine by hematoxylin-eosin alone. The independent variable is PTEN expression and the dependent variable is risk grade group Gleason prostate adenocarcinoma.

The grade group is a grouping of total Gleason scores into 5 groups: grade group 1 with Gleason score $\leq 6$, grade group 2 with Gleason score $3+4=7$, grade group 3 with Gleason score $4+3=7$, grade group 4 with Gleason score $4+4=8,3+5=8,5+3=8$, and grade group 5 with Gleason score 9-10. Then, we group this Gleason scores into 3 categories based on NCCN (National Comprehensive Cancer Network) risk stratification: low risk grade group Gleason (Gleason score $\leq 6$ ), intermediate risk grade group Gleason (Gleason score 7), and high risk grade group Gleason (Gleason score 8-10).

\section{Immunohistochemistry}

PTEN (Phosphatase and Tensin Homologue) expression is the expression of PTEN protein examined by the immunohistochemical technique, using an antiPTEN monoclonal antibody (6H2.1) mouse primary antibody and evaluated with Olympus CX31 LED binocular light microscope. The percentage of PTEN expression was assessed by low magnification ( $x 40)$ and the intensity was assessed by high magnification (x400). The PTEN protein status was visually scored by a twopathologist blinded to clinical data. The prostate tissue is considered to have intact PTEN when the PTEN protein is expressed in $>90 \%$ of sampled tumor glands. The prostate tissue is considered to have a loss of PTEN when the intensity of cytoplasmic and nuclear staining is markedly lower or entirely negative across $>10 \%$ of tumor cells compared to surrounding benign tissues and/or stroma, which provide internal positive controls. If PTEN is lost in $<100 \%$ of the tumor cells sampled, that is annotated as showing heterogeneous PTEN (focal loss). Alternatively, if PTEN is lost in $100 \%$ of tumor cells sampled, that is annotated as showing homogeneous PTEN loss $[7,9]$.

\section{Statistical Analysis}

The data were analyzed using the SPSS (Statistical Package for the Social Sciences) program 20.0 for Windows. The association between PTEN expression and risk grade group Gleason was analyzed using the logistic regression. 


\section{RESULTS}

During this study, we found 86 patients with prostate adenocarcinoma that consist of 83 acinar adenocarcinoma cases, 1 ductal adenocarcinoma case, and 2 mixed acinar and ductal adenocarcinoma cases. We select 35 samples based on inclusion and exclusion criteria. The youngest age is 46 years old and the oldest age is 83 years. The mean age is $69.60 \pm 8.4$ years and median 72 years.

Based on serum PSA, there were 3 cases (8.6\%) with PSA 0-9 $\mathrm{ng} / \mathrm{ml}, 2$ cases (5.7\%) with PSA 10-20 $\mathrm{ng} / \mathrm{ml}$, and 18 cases $(51.4 \%)$ with PSA $>20 \mathrm{ng} / \mathrm{ml}$. There were 12 samples $(34.3 \%)$ that did not have serum PSA data. Based on the histopathological diagnosis, these samples consist of 34 acinar adenocarcinoma cases and 1 ductal adenocarcinoma case. Based on the grade group Gleason, there were 5 cases (14.3\%) with grade group 1,4 cases (11.4\%) with grade group 2, 2 cases (5.7\%) with grade group 3, 3 cases (8.6\%) with grade group 4 , and 21 cases $(60 \%)$ with grade group 5 . Then, they were grouped into 3 categories: 5 cases $(14.3 \%)$ in the low risk grade group Gleason (Gleason score $\leq 6), 6$ cases $(17.1 \%)$ in the intermediate risk grade group Gleason (Gleason score 7); and 24 cases (68.6\%) in the high risk grade group Gleason (Gleason score 8-10).

There were 5 cases (14.3\%) with intact PTEN expression and 30 cases (85.7\%) with the loss of PTEN expression (22 cases of heterogeneous loss and 8 cases of homogeneous loss). The examples of the intact PTEN expression, heterogeneous and homogeneous loss of PTEN expression can be seen in Figure 1.

The distribution of risk grade group Gleason prostate adenocarcinoma based on patient age and serum PSA can be seen in Table 1. There is no association between risk grade group Gleason and patient age $(p=0.397)$, but it is associated with serum PSA $(p=0.001)$. The distribution of PTEN expression based on prostate adenocarcinoma grade groups, patient age and serum PSA can be seen in Table 2. There was association between PTEN expression and risk grade group Gleason $(p=0.001)$ and serum PSA $(p=0.016)$, but it wasn't associated with patient age. The distribution of the loss of PTEN expression heterogeneously and homogeneously based on risk grade group Gleason prostate adenocarcinoma, patient age and serum PSA can be seen in Table 3. This study found there was no association between the loss of PTEN expression heterogeneously or homogenously and risk grade group Gleason prostate adenocarcinoma $(p=0.742)$, patient age $(p=0.272)$ and serum PSA $(p=0.314)$.
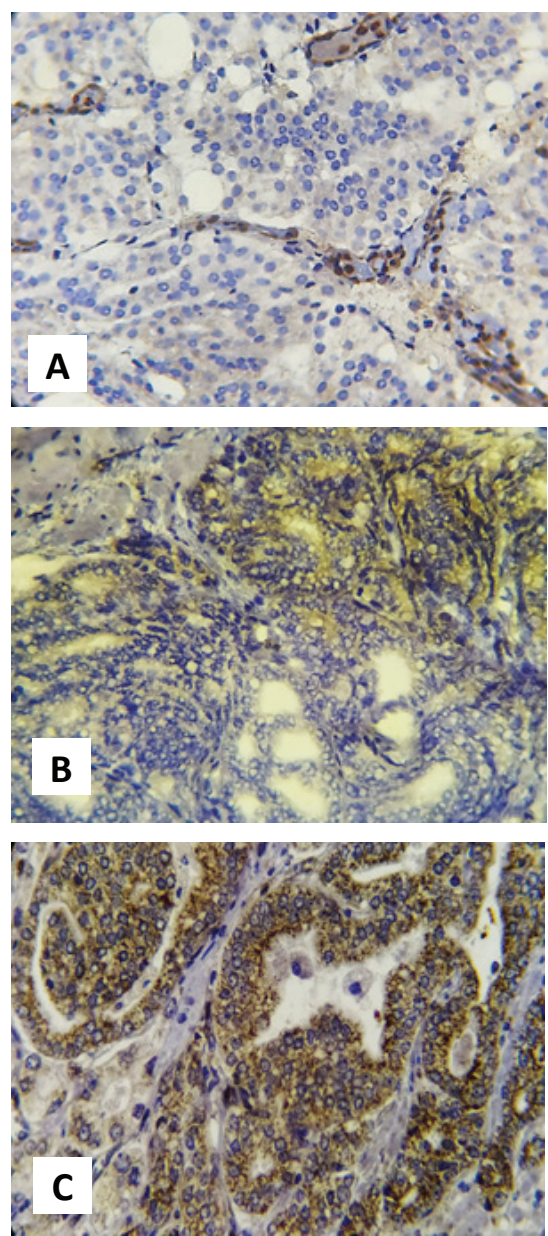

Figure 1. PTEN expression from immunohistochemistry. A. Intact PTEN expression (400x). B. Heterogeneously loss of PTEN expression (400x). C. Homogeneously loss of PTEN expression (400x).

Table 1. Distribution of risk grade group Gleason prostate adenocarcinoma according to patient age and serum PSA

\begin{tabular}{|c|c|c|c|c|}
\hline & \multicolumn{3}{|c|}{ Risk grade group Gleason } & \multirow{2}{*}{$\mathbf{p}$} \\
\hline & Low (Gleason score $\leq 6$ ) & Intermediate (Gleason score 7) & High (Gleason score 8-10) & \\
\hline Patient's age & & & & 0.397 \\
\hline $40-49$ & $0(0 \%)$ & $0(0 \%)$ & $1(4.2 \%)$ & \\
\hline $50-59$ & $0(0 \%)$ & $0(0 \%)$ & $3(12.5 \%)$ & \\
\hline $60-69$ & $3(60 \%)$ & $3(50 \%)$ & $6(25 \%)$ & \\
\hline $70-79$ & $2(40 \%)$ & $1(16.7 \%)$ & $12(50 \%)$ & \\
\hline $80-89$ & $0(0 \%)$ & $2(33.3 \%)$ & $2(8.3 \%)$ & \\
\hline Serum PSA & & & & 0.001 \\
\hline 0-9 ng/ml & $2(66.7 \%)$ & $1(33.3 \%)$ & $0(0 \%)$ & \\
\hline $10-20 \mathrm{ng} / \mathrm{ml}$ & $1(33.3 \%)$ & $1(33.3 \%)$ & $0(0 \%)$ & \\
\hline$>20 \mathrm{ng} / \mathrm{ml}$ & $0(0 \%)$ & $1(33.3 \%)$ & $17(100 \%)$ & \\
\hline
\end{tabular}


Table 2. Distribution of PTEN expression according to risk grade group Gleason of prostate adenocarcinoma, patient age and serum PSA

\begin{tabular}{|c|c|c|c|c|c|}
\hline & \multicolumn{2}{|c|}{ PTEN expression } & \multirow{2}{*}{ PR } & \multirow{2}{*}{$95 \% \mathrm{Cl}$} & \multirow{2}{*}{$\mathbf{p}$} \\
\hline & Intact & Loss & & & \\
\hline Risk grade group Gleason & & & \multirow{4}{*}{3.339} & \multirow{4}{*}{$(1.296-8.599)$} & 0.001 \\
\hline Low (Gleason score $\leq 6$ ) & $3(60 \%)$ & $2(6.7 \%)$ & & & \\
\hline Intermediate (Gleason score 7) & $2(40 \%)$ & $4(13.3 \%)$ & & & \\
\hline High (Gleason score 8-10) & $0(0 \%)$ & $24(80 \%)$ & & & \\
\hline Patient's age & & & \multirow{6}{*}{0.642} & \multirow{6}{*}{$(0.203-2.028)$} & 0.893 \\
\hline $40-49$ & $0(0 \%)$ & $1(3.3 \%)$ & & & \\
\hline $50-59$ & $0(0 \%)$ & $3(10 \%)$ & & & \\
\hline $60-69$ & $2(40 \%)$ & $10(33.3 \%)$ & & & \\
\hline 70-79 & $2(40 \%)$ & $13(43.3 \%)$ & & & \\
\hline $80-89$ & $1(20 \%)$ & $3(10 \%)$ & & & \\
\hline Serum PSA & & & \multirow{4}{*}{6.191} & \multirow{4}{*}{$(1.298-29.520)$} & 0.016 \\
\hline $0-9 \mathrm{ng} / \mathrm{ml}$ & $2(50 \%)$ & $1(5.3 \%)$ & & & \\
\hline $10-20 \mathrm{ng} / \mathrm{ml}$ & $1(25 \%)$ & $1(5.3 \%)$ & & & \\
\hline$>20 \mathrm{ng} / \mathrm{ml}$ & $1(25 \%)$ & $17(56.7 \%)$ & & & \\
\hline
\end{tabular}

Table 3. Distribution of loss of PTEN expression heterogeneously and homogeneously according to risk grade group Gleason prostate adenocarcinoma, patient age and serum PSA

\begin{tabular}{|c|c|c|c|c|c|}
\hline & \multicolumn{2}{|c|}{ Loss of PTEN expression } & \multirow{2}{*}{ PR } & \multirow{2}{*}{$95 \% \mathrm{Cl}$} & \multirow{2}{*}{$\mathbf{p}$} \\
\hline & Heterogen & Homogen & & & \\
\hline Risk grade group Gleason & & & \multirow{4}{*}{0.663} & \multirow{4}{*}{$(0.179-2.457)$} & 0.742 \\
\hline Low (Gleason score $\leq 6$ ) & $1(4.5 \%)$ & $1(12.5 \%)$ & & & \\
\hline Intermediate (Gleason score 7) & $3(13.6 \%)$ & $1(12.5 \%)$ & & & \\
\hline High (Gleason score 8-10) & $18(81.8 \%)$ & $6(75 \%)$ & & & \\
\hline Patient's age & & & \multirow{6}{*}{0.579} & \multirow{6}{*}{$(0.236-1.424)$} & 0.272 \\
\hline $40-49$ & $1(4.5 \%)$ & $0(0 \%)$ & & & \\
\hline $50-59$ & $2(9.1 \%)$ & $1(12.5 \%)$ & & & \\
\hline $60-69$ & $5(22.7 \%)$ & $5(62.5 \%)$ & & & \\
\hline 70-79 & $11(50 \%)$ & $2(25.0 \%)$ & & & \\
\hline $80-89$ & $3(13.6 \%)$ & $0(0 \%)$ & & & \\
\hline Serum PSA & & & \multirow{4}{*}{1.108} & \multirow{4}{*}{$(0.157-7.824)$} & 0.314 \\
\hline $0-9 \mathrm{ng} / \mathrm{ml}$ & $1(8.3 \%)$ & $0(0 \%)$ & & & \\
\hline $10-20 \mathrm{ng} / \mathrm{ml}$ & $0(0 \%)$ & $1(14.3 \%)$ & & & \\
\hline$>20 \mathrm{ng} / \mathrm{ml}$ & 11 (91.7\%) & 6 (85.7\%) & & & \\
\hline
\end{tabular}

\section{DISCUSSION}

In this study, the risk grade group Gleason and PTEN expression weren't associated with patient age. Trock et al. [11] also found no significant association between grade group and age. Age is associated with the increased risk of developing prostate cancer, but not with the grade group. Factors that influence the progression of prostate cancer include androgen receptor, growth factor, invasive and metastasis gene (such as PTEN, NKX3.1). PTEN is a tumor suppressor gene that inhibits phosphoinositide 3-kinase-RAC-alpha serine/threonine-protein kinase (PI3K/AKT). Cell growth, cell proliferation, survival and cell migration may occur when PTEN is inactivated [12]. 
Trock et al. [11] also found the association between risk grade group Gleason and serum PSA similar with this study. They found a significant association between the grade group and serum PSA with PTEN expression based on an immunohistochemical examination. In general, serum PSA is associated with a greater tumor volume, a more advanced pathology stage and a higher tumor grade. Although higher grade cancer produces lower PSA per cell compared to lower grade cancer, overall, poorly differentiated tumors are associated with higher PSA levels because these tumors tend to be larger and of more advanced stage [13].

This study found PTEN expression was associated with risk grade group Gleason, but there was no association between the heterogeneous or homogeneous loss of PTEN expression and risk grade group Gleason. The PTEN activity on plasma membrane is a key factor because PTEN can influence the amount of PIP3, downstream activities of the AKT and mTOR signal cascade and contribute to the PIP3-PIP2 gradient. PTEN was also reported to regulate annexin2 (ANXA2) and CDC42 and atypical PKC (aPKC) to maintain apex-basal polarity during epithelial morphogenesis, so inactivation of PTEN can cause the cell loss of polarity and tight junction [14]. Lotan et al. [7] found that the PTEN status on immunohistochemical examination was related to clinicopathological factors, including Gleason score and pathology stage. They also found that the homogeneous loss of PTEN was significantly related to shorter recurrence-free survival compared to intact PTEN expression and the heterogeneous loss of PTEN, which showed a slight difference from our result. This condition may be due to the immunohistochemical examination that is less sensitive than FISH in distinguishing the homogeneous and heterogeneous loss of PTEN. Intratumoral heterogeneity can occur in $50 \%$ of primary prostate cancers that can be one of the important reasons that explain why the homogeneous and heterogeneous loss of PTEN expression is not significantly associated with grade groups. The immunohistochemical examination is only limited to detecting protein concentration and the amount of protein detected can be influenced by various non-biological factors such as tissue quality, protein preservation, antibody concentration and retrieval antigen efficacy [9].

This study found a statistically significant association between PTEN expression and serum PSA, where high serum PSA values are associated with loss of PTEN expression, but there is no association between the heterogeneous or homogeneous loss of PTEN expression and serum PSA. This result is consistent with the study conducted by Lotan et al. [9] They found a statistically significant relationship between PTEN expression and grade group Gleason, PSA level, stage, metastasis to lymph nodes and resection limits. This relationship might be due to the expression of PTEN related to the grade group, so indirectly the expression of PTEN is also related to serum PSA. This study has proved that PTEN expression evaluated by immunohistochemical staining is associated with risk grade group Gleason prostate adenocarcinoma but does not depend on the heterogeneous or homogeneous loss of PTEN expression.

This study had several limitations. Given that prostate adenocarcinoma is a genetically heterogeneous and multifocal study is limited by sampling errors, this study has small sample size, resulting in limited statistical power. Therefore, larger studies are required to validate these findings.

\section{CONCLUSIONS}

This study has proved that PTEN expression is associated with risk grade group Gleason prostate adenocarcinoma.

\section{DECLARATIONS}

\section{Competing of Interest}

The authors declare no competing interest in this study.

\section{Acknowledgement}

The Authors wish to thank to Head of Laboratory Anatomical Pathology Sanglah Hospital Denpasar and all staffs that have contributed, so this research has been done.

\section{REFERENCES}

1. Humprey PA, Amin MB, Berney DM, Billis A, Cao D, Cheng L. Acinar adenocarcinoma. In. Moch H, Humprey PA, Ulbright TM, Reuter VE, editors. WHO Classification of Tumours of the Urinary System and Male Genital Organs. 4th Edition. France: Lyon; 2016. p. 138-162.

2. Umbas R, Hardjowijoto $S$, Mochtar CA, Safriadi F, Soesanto WD, Soedarsp MA, Danarto, Sihombing AT, Hamid AR, Sudoyo AW, Tadjoedin H, Syafei $S$, Gondhowiardjo S, Munandar A, Kodrat H, Nuhonni $\mathrm{SA}$, Indriani, Pratiwi KBH, Dewi FL, Witjaksono F, Manikam NRM, Octovia LI, Rani NA. Pedoman nasional pelayanan kedokteran kanker prostat. Jakarta: Kementerian Kesehatan Republik Indonesia; 2017.

3. McKenney JK. Prostate and Seminal Vesicles. In: Goldblum JR, Lamps LW, McKenney JK, Myers JL, editors. Rosai and Ackerman's Surgical Pathology. Eleventh edition. Philadelpia: Elsevier; 2018. p. 1097122. 
4. Djawaria FPA, Saputra H, Susraini AAAN. Loss of PTEN Expression as a Predictive Factor for Poor Clinical Response of Neoadjuvant Chemotherapy in Triple Negative Breast Cancer. IJSR. 2017;2319-7064.

5. Geybels MS, Fang M, Wright JL, Qu X, Bibikova M, Klotzle B. PTEN loss is associated with prostate cancer recurrence and alterations in tumor DNA methylation profiles. Oncotarget. 2017;8(48):84338-48.

6. Jamaspishvili $T$, Berman DM, Ross $A E$, Scher $H I$, Marzo AMD, Squire JA. Clinical implications of PTEN loss in prostate cancer. 2018. Macmillan: Springer Nature Reviews Urology. www.nature.com/nrurol.

7. Lotan TL, Wei W, Morais CL, Hawley ST, Fazli L, Coll AH, Troyer D, McKenney JK, Simko J, Carroll PR, Gleave M, Lance R, Lin DW, Nelson PS, Thompson IM, True LD, Feng Z, Brooks JD. Pten loss as determined by clinical-grade immunohistochemistry assay is associated with worse recurrence-free survival in prostate cancer. Eur Urol Focus. 2016;2:180-8.

8. Hamid AA, Gray KP, Huang Y, Bowden M, Pomerantz M, Loda M. Loss of PTEN Expression Detected by Fluorescence Immunohistochemistry Predicts Lethal Prostate Cancer in Men Treated with Prostatectomy. Eur Urol Oncol. 2018;2(5):475-82.

9. Lotan TL, Heumann A, Rico SD, Hicks J, Lecksell K, Koop C. PTEN loss detection in prostate cancer: comparison of PTEN immunohistochemistry and PTEN FISH in a large retrospective prostatectomy cohort. Oncotarget. 2017;8(39):65566-76.
10. Epstein JI, Zelefsky MJ, Sjoberg DD, Nelson JB, Egevad L, Galluzzi CM, Vickers AJ, Parwani AV, Reuter VE, Fine SW, Eastham JA, Wiklund P, Han M, Reddy CA, Ciezki JP, Nyberg T, Klein EA. A contemporary prostate cancer grading system: a validated alternative to the Gleason score. Eur Urol. 2016;69(3): 1-8.

11. Trock BJ, Fedor $H$, Gurel B, Jenkins RB, Knudsen BS, Fine SW, Said JW, Carter HB, Lotan TL, De Marzo AM. PTEN loss and chromosome 8 alterations in Gleason grade 3 prostate cancer cores predicts the presence of un-sampled grade 4 tumor: implications for active surveillance. Mod Pathol. 2016;29(7):764-71.

12. Hughes C, Murphy A, Martin C, Sheils O, O'Leary J. Molecular pathology of prostate cancer. J Clin Pathol. 2005;58:673-84.

13. Epstein JI, Cubilla AL, Humphrey PA. The normal prostate gland. In: Silverberg, S.G., Gardner, W.A., Sobin, L.H., editors. Tumors of the Prostate Gland, Seminal vesicles, Penis, and Scrotum. Fourth Series. Washington: American Registry of Pathology; 2011. p. 1-19.

14. Lee YR, Chen M, Pandolfi PP. The functions and regulation of the PTEN tumour suppressor: new modes and prospects. Macmillan: Springer Nature Reviews Molecular Cell Biology. 2018. 